\title{
Penggunaan SEM dan Image-J dalam Mempelajari Ketebalan Lapisan Mikrostruktur
}

\author{
Muhammad Iqbal ${ }^{1}$, Muhammad Firdaus ${ }^{1}$, Muhammad Al Fauzan ${ }^{1}$, Meilan Novayanti \\ Simanjuntak $^{1}$, Fathiyyah Syahidah $\mathbf{S}^{\mathbf{1}}$, M. Rifan Maulana ${ }^{1}$, Hana Mutialif Maulidiah ${ }^{1 *}$, Widya \\ Rika Puspita1, M. Mustanir $^{1}$, Adlian Jefiza', B. Budiana', dan Nur Sakinah Asaad ${ }^{1}$ \\ ${ }^{1}$ Jurusan Teknik Elektro, Batam, Indonesia \\ *Email: hana@polibatam.ac.id
}

\begin{abstract}
Telah dilakukan penelitian terkait dengan ketebalan lapisan mikrostruktur dengan menggunakan SEM (Scanning Electron Microscope) dan Image-J. Sampel diuji dengan menggunakan SEM untuk mendapatkan mikrostruktur dari sampel. Setelah mikrostruktur didapatkan maka dilakukan analisa ketebalan lapisan mikrostruktur dengan menggunakan teknik pengukuran secara langsung menggunakan SEM dan teknik pengukuran tidak langsung menggunakan aplikasi ImageJ. Berdasarkan hasil penelitian yang telah dilakukan, pengukuran ketebalan lapisan dengan menggunakan SEM dan Image-J menunjukkan pola kurva yang sama untuk semua ketebalan lapisan. Persentase perbedaan pengukuran ketebalan lapisan dengan menggunakan SEM dan Image $J$ adalah $0.7 \%$ untuk lapisan ke-1, 1,6 \% untuk lapisan ke-2 dan $0.8 \%$ untuk lapisan ke-3. Persentase perbedaan tersebut sangat kecil $(<2 \%)$ sehingga aplikasi Image-J ini dapat digunakan sebagai alternatif di dalam pengukuran ketebalan lapisan mikrostruktur.
\end{abstract}

Kata Kunci: Image-J, Ketebalan Lapisan, SEM

\section{Pendahuluan}

SALAH satu proses yang penting dalam perakitan komponen adalah proses solder. Ketika proses solder dilakukan, terdapat beberapa permasalahan yang terjadi seperti adanya defect atau crack pada bagian sambungan solder. Defect atau crack yang terjadi mengakibatkan perubahan terhadap material solder. Selain itu, defect akan mempengaruhi fungsionalitas dari produk komponen elektronika [1][2].

Timbulnya defect atau crack terjadi karena adanya pengaruh komposisi solder dan juga temperatur lingkungan sekitar. Pengamatan terhadap defect atau crack dapat dipelajari melalui kajian mikrostruktur (lapisan antar sambungan solder) dari susunan material solder. Salah satu karakterisasi yang dapat dilakukan adalah dengan menggunakan Scanning Electron Microscope (SEM). SEM merupakan metode yang efektif dalam menganalisis bahan organik dan anorganik pada skala mikrometer hingga nanometer dan juga dapat melakukan evaluasi mikrostruktur serta morfologi suatu material [3].

Konsep dasar SEM adalah dengan melakukan pemindaian permukaan sampel suatu material. Pemindaian sampel dilakukan dengan pemancaran berkas elektron pada permukaan material. Saat tumbukan elektron tersebut terjadi maka akan menghasilkan emisi foton dan elektron di sekitar permukaan sampel material tersebut [2].

Beberapa mode SEM yang dapat digunakan untuk karakterisasi material adalah pemetaan X-Ray, Secondary Electron, serta Backscattered Electron Imaging dan mikroskop elektron Auger [3]. Pemilihan mode SEM tergantung pada tujuan yang diharapkan dari sampel yang dibentuk. Salah satu hasil yang diperoleh dari karakterisasi yang dilakukan dengan menggunakan SEM adalah terlihatnya mikrostruktur dari sampel dengan ukuran tertentu.

Mikostruktur dari sampel dapat dilakukan analisa secara mendalam dengan menggunakan analisis elemen dan pengukuran ketebalan lapisan. Pengukuran ketebalan lapisan dapat merujuk pada warna dan tekstur yang terbentuk [4][5], [6].

Ketebalan untuk masing-masing lapisan pada mikrostruktur dapat diketahui melalui analisa SEM lanjutan. Namun, analisa lanjutan ini memerlukan waktu yang relatif lama dan juga akan meningkatkan biaya pengujian sehingga diperlukan solusi atas permasalahan tersebut.

Salah satu solusi yang dapat ditawarkan untuk pengukuran ketebalan lapisan adalah dengan menggunakan aplikasi ImageJ. Aplikasi ini telah berhasil dalam mempelajari citra/gambar dari mikostruktur sampel [7]. Pengolahan gambar dilakukan dengan menggunakan berbagai tools yang ada. Penelitianpenelitian yang berkaitan dengan penggunaan Image-J dalam mempelajari mikrostruktur telah dilakukan dalam kajian distribusi gambar [8], visual mikrostruktur [9], dan konstruksi struktur pipa [10]. Berdasarkan kajian yang telah dilakukan, penulis melakukan analisa terkait dengan penggunaan Image-J di dalam pengukuran ketebalan lapisan.

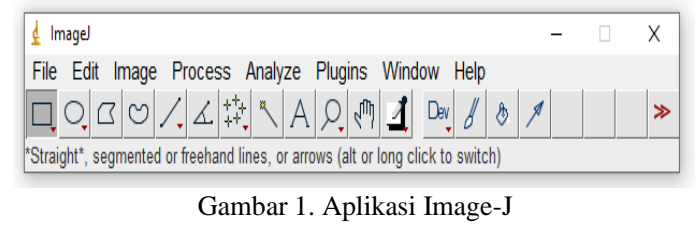




\section{Metode}

Metode penelitian yang dilakukan untuk pengukuran ketebalan lapisan terdiri dari dua metode yaitu metode penelitian dengan menggunakan SEM dan metode penelitian dengan menggunakan aplikasi Image-J.

\section{A. Pengukuran lapisan dengan menggunakan SEM}

Untuk mendapatkan mikrostruktur dari sampel maka dilakukan pengukuran dengan menggunakan SEM. Langkahlangkah yang dilakukan untuk mendapatkan mikrostruktur dari sampel dengan menggunakan Image-J ditunjukkan pada Gambar 2. Gambar 2 merupakan diagram alir penempatan komponen pada SEM untuk mendapatkan mikrostruktur dari sampel. Pengukuran ketebalan lapisan dilakukan dengan pengukuran langsung menggunakan SEM sedangkan pengukuran tidak langsung dengan menggunakan Image-J. SEM yang digunakan untuk pengukuran mikrostruktur ditunjukan pada Gambar 3. Sedangkan penempatan sampel pada holder ditunjukan pada Gambar 4. Adapun pengukuran tidak langsung dengan menggunakan Image-J ditunjukan pada Gambar 5.

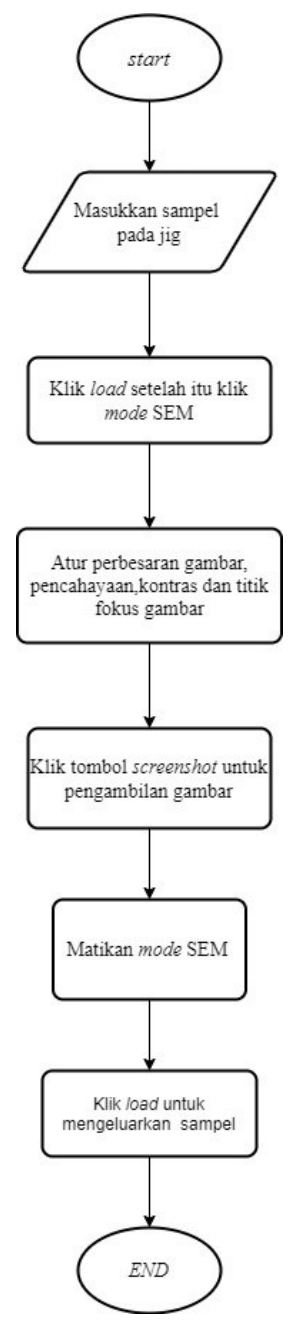

Gambar 2. Diagram Alir Pengujian Sampel dengan SEM

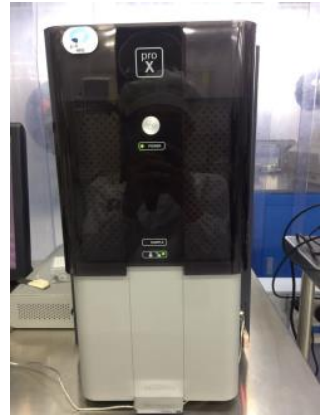

Gambar 3. Gambar SEM untuk Karakterisasi Mikrostruktur

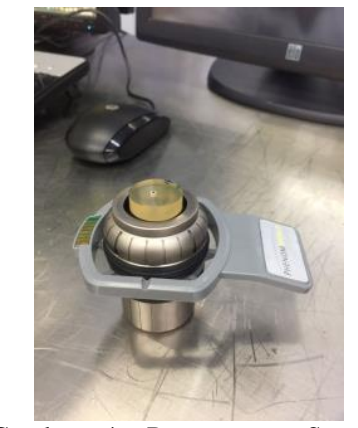

Gambar 4. Penempatan Sampel pada Holder

\section{B. Pengukuran lapisan dengan menggunakan Image-J}

Gambar yang telah diperoleh dengan menggunakan SEM kemudian diukur ketebalannya dengan menggunakan aplikasi Image-J secara tidak langsung. Diagram alir pengukuran ketebalan lapisan dengan menggunakan aplikasi Image-J dapat dilihat pada Gambar 5.

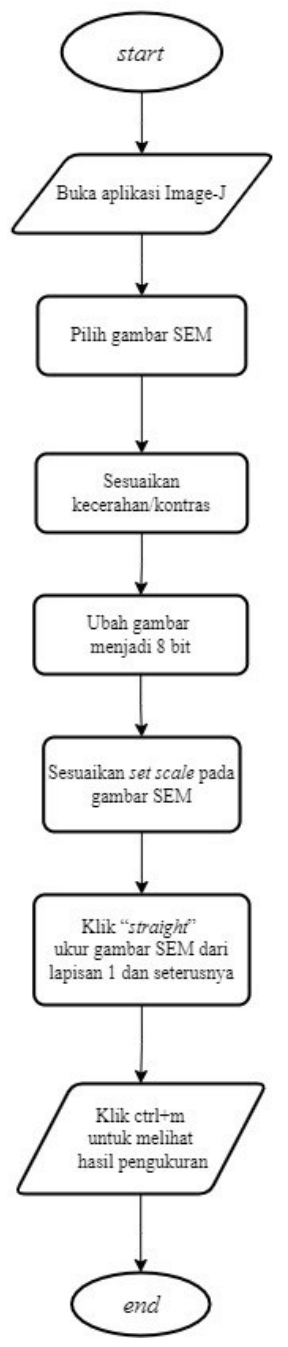

Gambar 5. Diagram Alir Analisa Gambar dengan Image-J 
Gambar 4 merupakan diagram alir pengukuran ketebalan lapisan dengan menggunakan Image-J. Pengolahan Gambar SEM diharapkan dapat memberikan infromasi mengenai ketebalan lapisan yang terbentuk pada sampel.

\section{HASIL DAN DISKUSI}

Berdasarkan pengukuran SEM yang telah dilakukan, mikrostruktur dari sampel ditunjukan pada Gambar 6.

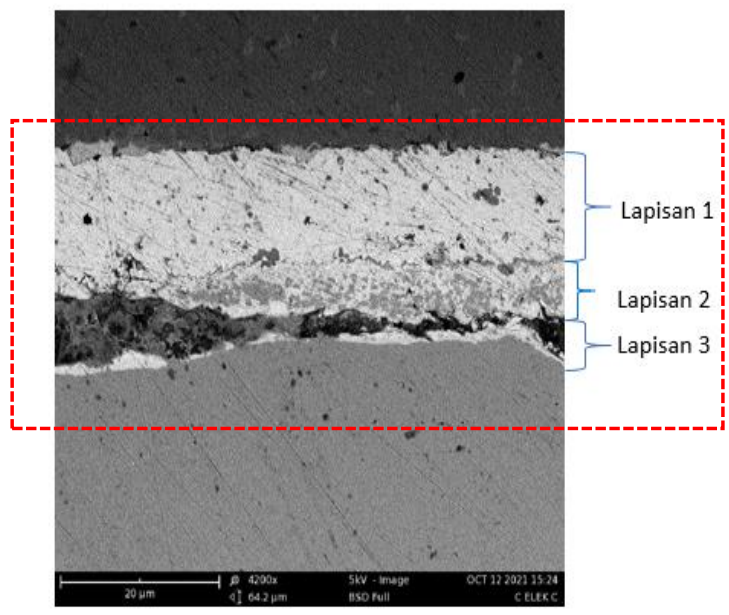

Gambar 6. Mikrostruktur Sampel

Terdapat tiga lapisan yang terbentuk. Lapisan yang terbentuk diklasifikasikan berdasarkan pada perbedaan morfologi (tekstur, warna, dan bentuk lapisan). Fokus daerah analisa berada pada daerah merah. Selain daerah merah, penulis tidak melakukan kajian secara komprehensif karena lapisan yang terbentuk (selain daerah merah) merupakan lapisan substrat yang telah diketahui pada analisa sebelumnya.

Masing-masing ketebalan lapisan diukur dengan menggunakan SEM dan Image-J. Pengukuran ketebalan dilakukan pada 10 titik gambar mikrostruktur. Pengukuran 10 titik yang dilakukan merujuk pada teori sampling dari suatu sampel. Contoh pengukuran ketebalan lapisan menggunakan SEM ditunjukkan pada Gambar 7 dan contoh pengukuran ketebalan lapisan menggunakan Image-J ditunjukkan pada Gambar 8. Untuk contoh hasil data pengukuran menggunakan Image-J dapat dilihat pada Gambar 9. Sedangkan untuk data pengukuran keseluruhan ditunjukan pada Tabel 1 dan 2 .

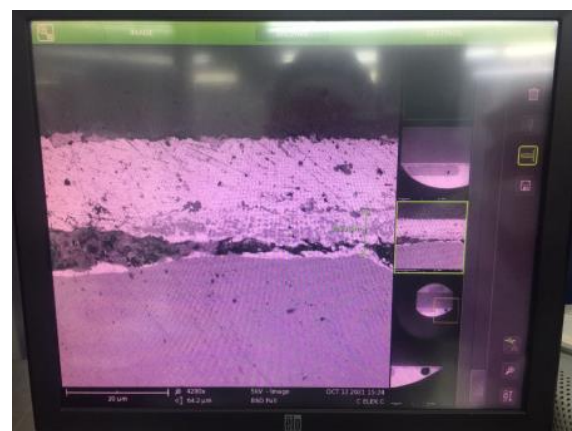

Gambar 7. Contoh pengambilan data pengukuran ketebalan dengan menggunakan SEM

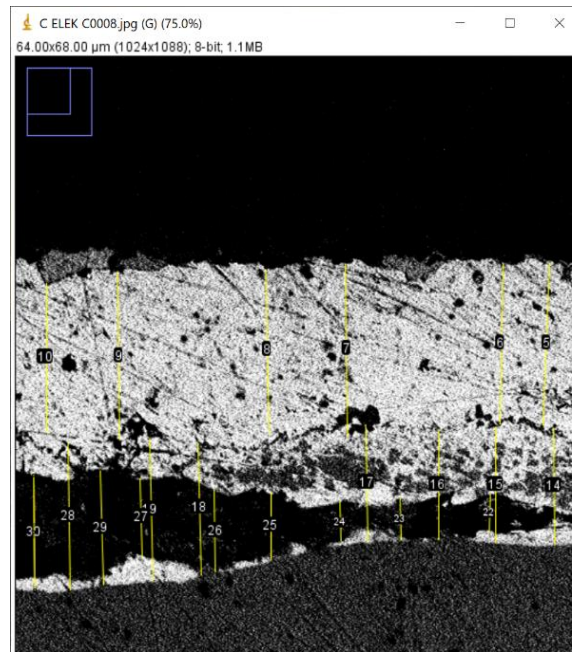

Gambar 8. Contoh Pengambilan Data Pengukuran Ketebalan dengan Menggunakan Image-J

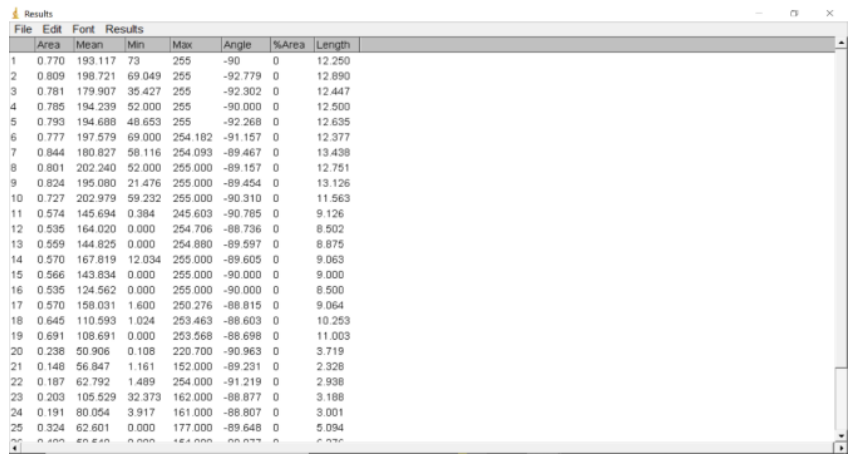

Gambar 9. Data Pengukuran Ketebalan Lapisan dengan Menggunakan Image$\mathrm{J}$

Adapun data pengukuran tebal lapisan dengan menggunakan SEM dan Image-J secara keseluruhan dapat dilihat pada Tabel 1 dan 2.

TABEL I

DATA PENGUKURAN TEBAL LAPISAN DENGAN MENGGUNAKAN SEM

\begin{tabular}{cccc}
\hline \multirow{3}{*}{ No } & \multicolumn{3}{c}{ Lapisan (um) ke- } \\
& 1 & 2 & 3 \\
\hline 1 & 12,25 & 9,12 & 2,32 \\
2 & 12,89 & 8,50 & 2,93 \\
3 & 12,44 & 8,87 & 3,18 \\
4 & 12,50 & 9,06 & 3,01 \\
5 & 12,60 & 9,04 & 5,09 \\
6 & 12,35 & 8,50 & 6,37 \\
7 & 13,43 & 9,05 & 6,07 \\
8 & 12,75 & 10,24 & 11,36 \\
9 & 13,13 & 10,95 & 8,88 \\
10 & 11,55 & 3,72 & 8,87 \\
\hline \hline
\end{tabular}


TABEL II

DATA PENGUKURAN TEBAL LAPISAN DENGAN MENGGUNAKAN IMAGE-J

\begin{tabular}{cccc}
\hline \multirow{3}{*}{ No } & \multicolumn{3}{c}{ Lapisan (um) ke- } \\
& 1 & 2 & 3 \\
\hline 1 & 12,25 & 9,13 & 2,33 \\
2 & 12,89 & 8,50 & 2,94 \\
3 & 12,45 & 8,88 & 3,19 \\
4 & 12,50 & 9,06 & 3,01 \\
5 & 12,63 & 9,00 & 5,09 \\
6 & 12,34 & 8,50 & 6,38 \\
7 & 13,44 & 9,06 & 6,06 \\
8 & 12,75 & 10,25 & 11,38 \\
9 & 13,13 & 11,03 & 8,88 \\
10 & 11,56 & 3,72 & 8,88 \\
\hline \hline
\end{tabular}

Data ketebalan untuk masing-masing lapisan diolah untuk mendapatkan nilai standar deviasi dan standar eror. Untuk perhitungan standar deviasi menggunakan rumus:

$$
\sigma=\sqrt{\frac{\sum(x-\bar{x})^{2}}{n-1}}
$$

Keterangan:

$\sigma \quad$ : standar deviasi

$\mathrm{x}$ : data pengukuran ke $\mathrm{n}$

$\bar{x} \quad$ : rata-rata pengukuran

n : banyaknya data pengukuran

Sedangkan, untuk standar eror menggunakan rumus:

$$
\mathrm{SE}=\frac{\sigma}{\sqrt{n}}
$$

Keterangan:

$$
\begin{array}{ll}
S E & : \text { standar eror } \\
\sigma & : \text { standar deviasi } \\
\mathrm{n} & \text { : banyaknya data pengukuran }
\end{array}
$$

Adapun hasil pengolahan data ketebalan masing-masing lapisan ditunjukan pada Tabel III dan Tabel IV.

TABEL III

PENGOLAHAN DATA STATISTIK TEBAL LAPISAN DENGAN SEM

\begin{tabular}{ccccc}
\hline \hline Variabel & $\begin{array}{c}\text { Jumlah } \\
\text { Data }\end{array}$ & Mean & SE Mean & StDev \\
\hline Lapisan 1 & 10 & 12.589 & 0.163 & 0.516 \\
Lapisan 2 & 10 & 8.705 & 0.604 & 1.912 \\
Lapisan 3 & 10 & 5.808 & 0.976 & 3.086 \\
\hline \hline
\end{tabular}

TABEL IV

PENGOLAHAN DATA STATISTIK TEBAL LAPISAN DENGAN IMAGE-J

\begin{tabular}{ccccc}
\hline \hline Variabel & $\begin{array}{c}\text { Jumlah } \\
\text { Data }\end{array}$ & Mean & SE Mean & StDev \\
\hline Lapisan 1 & 10 & 12.594 & 0.163 & 0.516 \\
Lapisan 2 & 10 & 8.713 & 0.608 & 1.923 \\
Lapisan 3 & 10 & 5.814 & 0.977 & 3.088 \\
\hline \hline
\end{tabular}

Berdasarkan pada Tabel III dan IV, standar eror dan standar deviasi cenderung kecil $(<5)$ untuk kedua teknik pengukuran baik dengan menggunakan pengukuran SEM maupun dengan Image-J. Standar eror menyatakan tingkat akurasi distribusi suatu sampel yang mewakili suatu populasi sedangkan standar deviasi menyatakan ukuran sebaran statistik serta melihat ratarata jarak penyimpangan dari nilai rata-rata suatu sampel. Berdasarkan hal tersebut, data yang didapatkan dari hasil penelitian mendekati nilai rata-rata dari suatu sampel sehingga nilai variansi pengukuran tidak menyebar. Untuk pengukuran ketebalan lapisan sendiri, seharusnya nilai tersebut mengerucut pada suatu titik atau ketebalan lapisan yang terbentuk harus memiliki nilai yang sama sepanjang lapisan yang terbentuk. Jika ketebalan lapisan yang terbentuk bervariasi, ini menandakan adanya proses difusi yang tidak seragam selama proses soldering terjadi. Jika distribusi lapisan berbeda-beda, kemungkinan distribusi pembebanan baik secara mekanik maupun termal akan berbeda. Jika hal ini terus berlanjut, kemungkinan yang terjadi adalah crack lapisan [11].

Untuk melihat pola kurva yang terbentuk antara pengukuran ketebalan dengan menggunakan SEM dan Image-J, maka disusun kurva yang ditunjukkan pada Gambar 10-12. Tujuan kurva dibuat untuk mendapatkan korelasi antara dua teknik pengukuran yang dilakukan.

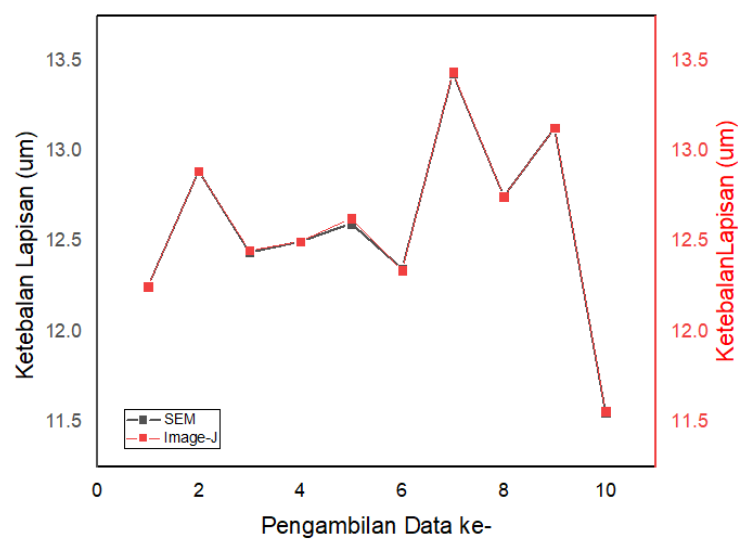

Gambar 10. Kurva yang terbentuk antara pengambilan data ke-n dengan ketebalan lapisan menggunakan SEM dan Image-J pada lapisan ke-1

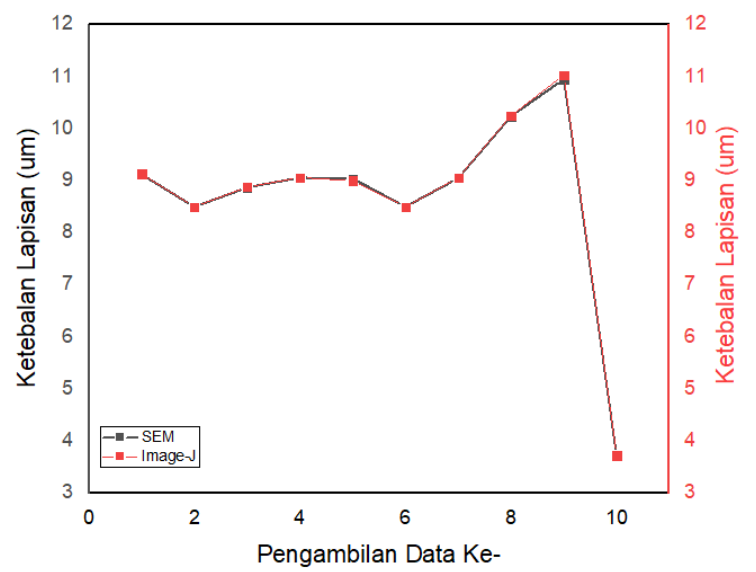

Gambar 11. Kurva yang terbentuk antara Pengambilan data ke-n dengan ketebalan lapisan menggunakan SEM dan Image-J pada lapisan ke-2 


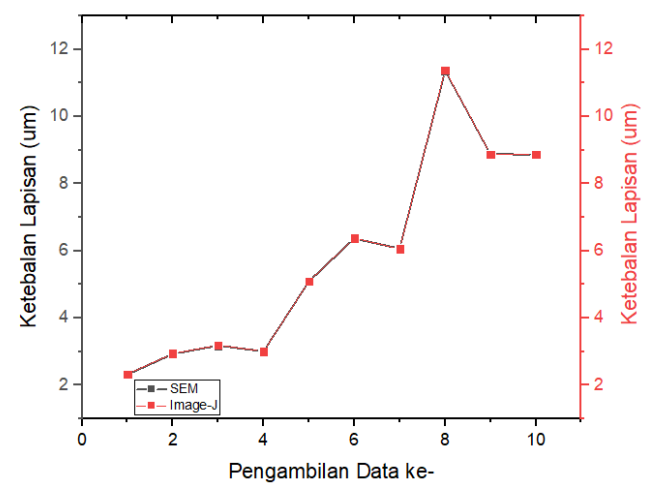

Gambar 12. Kurva yang terbentuk antara pengambilan data ke-n dengan ketebalan lapisan menggunakan SEM dan Image-J pada lapisan ke-3

Merujuk pada Gambar 10-12, dua kurva terlihat berimpit satu dengan yang lainnya sehingga kurva yang terbentuk memiliki kecenderungan yang sama dari bentuk dan titik koordinatnya. Hal ini menunjukkan pengukuran dengan menggunakan Image$\mathrm{J}$ dapat digunakan untuk pengukuran ketebalan lapisan mikrostruktur. Nilai persentase perbedaan pengukuran ketebalan lapisan ditunjukkan pada Tabel V-VII.

TABEL V

PERSENTASE PERBEDAAN PENGUKURAN KETEBALAN LAPISAN KE-1 DENGAN MENGGUNAKAN SEM DAN IMAGE-J

\begin{tabular}{cccc}
\multicolumn{4}{c}{ MENGGUNAKAN SEM DAN IMAGE-J } \\
\hline \hline \multirow{2}{*}{ No } & SEM & Image-J & Perbedaan (\%) \\
\cline { 2 - 3 } & $\begin{array}{c}\text { Ketebalan } \\
\text { Lapisan (um) }\end{array}$ & $\begin{array}{c}\text { Ketebalan } \\
\text { Lapisan (um) }\end{array}$ & \\
\hline 1 & 12,25 & 12,25 & 0 \\
2 & 12,89 & 12,89 & 0 \\
3 & 12,44 & 12,45 & 1 \\
4 & 12,50 & 12,50 & 0 \\
5 & 12,60 & 12,63 & 3 \\
6 & 12,35 & 12,34 & 1 \\
7 & 13,43 & 13,44 & 1 \\
8 & 12,75 & 12,75 & 0 \\
9 & 13,13 & 13,13 & 0 \\
10 & 11,55 & 11,56 & 1 \\
\hline \multicolumn{5}{c}{ Rata-Rata } \\
\hline \hline
\end{tabular}

TABEL VI

PERSENTASE PERBEDAAN PENGUKURAN KETEBALAN LAPISAN KE-2 DENGAN MENGGUNAKAN SEM DAN IMAGE-J

\begin{tabular}{cccc}
\hline \multicolumn{3}{c}{ MENGGUNAKAN SEM DAN IMAGE-J } \\
\hline \hline \multirow{2}{*}{ No } & SEM & Image-J & Perbedaan (\%) \\
\cline { 2 - 3 } & $\begin{array}{c}\text { Ketebalan } \\
\text { Lapisan (um) }\end{array}$ & $\begin{array}{c}\text { Ketebalan } \\
\text { Lapisan (um) }\end{array}$ & \\
\hline 1 & 9,12 & 9,13 & 1 \\
2 & 8,50 & 8,50 & 0 \\
3 & 8,87 & 8,88 & 1 \\
4 & 9,06 & 9,06 & 0 \\
5 & 9,04 & 9,00 & 4 \\
6 & 8,50 & 8,50 & 0 \\
7 & 9,05 & 9,06 & 1 \\
8 & 10,24 & 10,25 & 1 \\
9 & 10,95 & 11,03 & 8 \\
10 & 3,72 & 3,72 & 0 \\
\hline \multicolumn{4}{c}{ Rata-Rata } \\
\hline \hline
\end{tabular}

TABEL VII

PERSENTASE PERBEDAAN PENGUKURAN KETEBALAN LAPISAN KE-3 DENGAN MENGGUNAKAN SEM DAN IMAGE-J

\begin{tabular}{|c|c|c|c|}
\hline \multirow[b]{2}{*}{ No } & SEM & Image-J & \multirow{2}{*}{ Perbedaan $(\%)$} \\
\hline & $\begin{array}{c}\text { Ketebalan } \\
\text { Lapisan (um) }\end{array}$ & $\begin{array}{l}\text { Ketebalan } \\
\text { Lapisan (um) }\end{array}$ & \\
\hline 1 & 2,32 & 2,33 & 1 \\
\hline 2 & 2,93 & 2,94 & 1 \\
\hline 3 & 3,18 & 3,19 & 1 \\
\hline 4 & 3,01 & 3,01 & 0 \\
\hline 5 & 5,09 & 5,09 & 0 \\
\hline 6 & 6,37 & 6,38 & 1 \\
\hline 7 & 6,07 & 6,06 & 1 \\
\hline 8 & 11,36 & 11,38 & 2 \\
\hline 9 & 8,88 & 8,88 & 0 \\
\hline 10 & 8,87 & 8,88 & 1 \\
\hline & Rata-Rat & & 0,8 \\
\hline
\end{tabular}

Untuk rata-rata persentase perbedaan pengukuran ketebalan semua lapisan ditunjukkan pada Gambar 12.

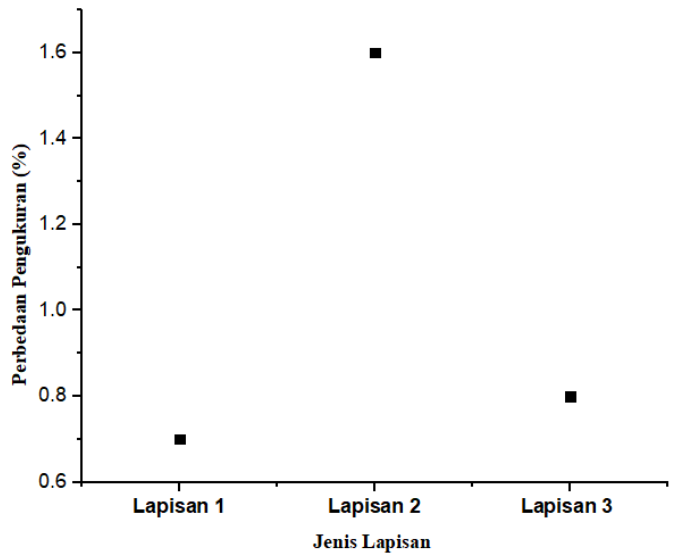

Gambar 12. Kurva yang terbentuk antara jenis lapisan dan persentase perbedaan pengukuran ketebalan antara menggunakan SEM dan Image-J

Merujuk pada Tabel V-VII, nilai rata-rata persentase perbedaan pengukuran ketebalan lapisan $<2 \%$. Hasil ini menunjukkan bahwa pengukuran ketebalan lapisan mikrostruktur dengan SEM dan Image-J mendekati sama. Sehingga teknik pengukuran dengan menggunakan Image-J dapat dijadikan sebagai salah satu teknik pengukuran ketebalan lapisan mikrostruktur.

\section{KESIMPULAN}

Penelitian terkait penggunaan SEM dan Image-J dalam mempelajari ketebalan lapisan mikrostruktur telah berhasil dilakukan. Hasil penelitian menunjukan bahwa pengukuran ketebalan lapisan mikrostruktur dengan menggunakan SEM mendekati sama dengan pengukuran ketebalan lapisan dengan menggunakan Image-J, baik dari bentuk kurva yang terbentuk maupun titik koordinatnya. Persentase perbedaan pengukuran ketebalan lapisan antara SEM dan Image-J adalah 0,7 \% untuk lapisan ke-1; 1,6\% untuk lapisan ke-2; dan 0,8\% untuk lapisan ke-3. Persentase perbedaan pengukuran $<2 \%$ sehingga Image-J dapat digunakan sebagai alternatif pada pengukuran ketebalan lapisan mikrostruktur. 


\section{REFERENSI}

[1] S. Teng, C. Guirguis, G. Ramakrishna, and H. Ly, "Investigation of Solder Joint Encapsulant Materials for Defect Mitigation," Journal of Surface Mount Technology, vol. 33, no. 1, pp. 20-27, Jul. 2020, doi: 10.37665/SMT.V33I1.3.

[2] G. S. Wable, S. Chada, B. Neal, and R. A. Fournelle, "Solidification shrinkage defects in electronic solders," JOM 2005 57:6, vol. 57, no. 6, pp. 38-42, 2005, doi: 10.1007/S11837-005-0134-X.

[3] S. A. Sayid, A. Dadan-Garba, D. E. Enenche, and B. A. Ikyo, "Scanning Electron Microscopy (SEM) of the Bug Eye and Sand Coral," undefined, vol. 08, no. 01, pp. 1-7, 2020, doi: 10.4236/MR.2020.81001.

[4] A. A. Bogno, J. E. Spinelli, C. R. M. Afonso, and H. Henein, "Microstructural and mechanical properties analysis of extruded $\mathrm{Sn}-$ 0.7Cu solder alloy," Journal of Materials Research and Technology, vol. 4, no. 1, pp. 84-92, Jan. 2015, doi: 10.1016/J.JMRT.2014.12.005.

[5] O. Mokhtari and H. Nishikawa, "Effects of in and $\mathrm{Ni}$ addition on icrostructure of Sn-58Bi solder joint," Journal of Electronic Materials, vol. 43, no. 11, pp. 4158-4170, Nov. 2014, doi: 10.1007/S11664-0143359-Z.

[6] U. Ali, H. Khan, M. Aamir, K. Giasin, N. Habib, and M. Owais Awan, "Analysis of Microstructure and Mechanical Properties of Bismuth-
Doped SAC305 Lead-Free Solder Alloy at High Temperature," Metals 2021, Vol. 11, Page 1077, vol. 11, no. 7, p. 1077, Jul. 2021, doi: 10.3390/MET11071077.

[7] B. Budiana, F. Nakul, N. Wivanius, B. Sugandi, and R. Yolanda, "Analisis Kekasaran Permukaan Besi ASTM36 dengan menggunakan Surftest dan Image -J," Journal of Applied Electrical Engineering, vol. 4, no. 2, pp. 49-54, Dec. 2020, doi: 10.30871/JAEE.V4I2.2747.

[8] M. A. Hossain, P. Khan, C. C. Lu, and R. J. Clements, "Distributed ImageJ (Fiji): A framework for parallel image processing," IET Image Processing, vol. 14, no. 12, pp. 2937-2947, Oct. 2020, doi: 10.1049/IET-IPR.2019.0150/CITE/REFWORKS.

[9] A. Ullah, G. Liu, H. Wang, D. F. Khan, and M. Khan, "A framework for image processing, analysis and visualization of materials microstructures using ImageJ package," undefined, 2012.

[10] T. Qasim, C. Ford, M. Bongué-Boma, M. B. Bush, and X. Z. Hu, "Effect of coating thickness on crack initiation and propagation in nonplanar bi-layers," Materials Science and Engineering A, vol. 419, no. 1-2, pp. 189-195, Mar. 2006, doi: 10.1016/J.MSEA.2005.12.023. 